\title{
How Are We Doing? Agency/University Collaboration for Assessment of Client Outcomes
}

\author{
Carol S. Cohen \\ Michael H. Phillips \\ Marianne Chierchio
}

\begin{abstract}
Assessment of client outcomes in social work practice has new urgency in today's service environment. However, traditional visions of agency staff as doers and social work educators as thinkers limit opportunities for collaboration. The Agency/University Collaboration model integrates doer and thinker roles, providing opportunities to both enhance assessment of client outcomes in practice and bring current practice knowledge into the social work classroom. An example of a multisite-parenting program illustrates how agency administrators and educators may forge collaborations. The authors discuss relevant issues, such as ownership of collaboration, appraisal of risks, and pacing the work.
\end{abstract}

Keywords: Collaboration, assessment, outcomes, agency, university

W Thile the need for expanded outcome assessment in social work practice is longstanding, it has new urgency in today's social service environment. Federal auditing requirements, managed care procedures, and grant regulations place increased demands on agencies to assess the effectiveness of their social work services (Chernesky, 1997; OAPP, 2001). Ensuring that vulnerable members of our society receive quality services is a high priority of the National Association of SocialWorkers (NASW). Indeed, in the Code of Ethics (1996, 1998), NASW directs social workers to evaluate their practice. The standards and policies of the Council on Social Work Education (COA, 1994) also require accredited programs of social work to teach students to become sophisticated consumers of research and to learn how to systematically evaluate their own services.

Austin's (1992) report of the NIMH Task Force on Social Work Research, and his subsequent review of research resources in social work (Austin, 1999), document the progress made by social work professional organizations and schools of social work in supporting the development of social workers skilled in research methods. However, Austin (1999) also notes that, "It is not clear that systematic dissemination of research-based information to the practice community is actually happening" (p. 693). The problems associated with incorporating research-based information and adopting research methods in agency-based practice may result from differ-

Carol S. Cohen, D.S.W., C.S.W. is Assistant Professor and Program Director, B.A. Program in Social Work, and Michael H. Phillips, D.S.W., C.S.W. is Professor, Fordham University Graduate School of Social Work. Marianne Chierchio, MSW, C.S.W. is Director of Training at Catholic Charities, Diocese of Brooklyn.

Copyright@ 2001 Advances in Social Work Vol. 2 No. 1 (Spring 2001) 12-25.

Indiana University School of Social Work. 
ences in the perspectives of academics and community practitioners. Witkin (1995) notes that although many faculty members value research, most social work students do not view research as relevant to the realities of practice and the values of the profession. Blythe (1992) observes that an agency's orientation to practice research is primarily determined by the individual perspectives of the professional staff. When social workers who hold a scientific practitioner perspective join an agency, the organization is more likely to become interested in research, assessment, and evaluation. Staff perspectives appear to be critical to the implementation of successful outcome assessment in agency cultures.

Social work agencies are traditionally viewed as developing innovative programs, generating funding, reaching clients, and delivering services. Agency-based social workers are considered doers who put plans into action. Lindsey and Kirk (1992) expand on these perceptions. They observe that the profession de-emphasizes research through an ideological bias that "favors action over theory, practice insight over scientific research, and good intentions over effective outcomes" (p. 378). The systematic assessment of client outcomes, seen as reflective rather than active, is often given low priority. This marginalization of assessment is exacerbated when agencies face multiple demands and possess limited resources.

While agency-based social workers may be viewed as doers, university-based researchers and educators tend to be thinkers who inhabit the world of ideas and use agencies as testing sites for favorite theories. This notion of the academic as primarily thinking, may be associated with the ivory tower metaphor and practitioners' sense of the real world, as opposed to the unreal world of the classroom. Ironically, the doer and thinker frames of reference may also exist in the academic world. Much of the research activity within social work faculties can be traced to a relatively small cohort of "highly productive social work researchers, while many social work educators and practitioners rarely conduct research" (Fraser, Jenson \& Lewis, 1993, p. 47).

Clearly, the doer and thinker dichotomy serves neither group well. Indeed, social workers in agency practice continually use their thinking skills, and universitybased educators cannot become proficient researchers in a vacuum. The thinker/doer myth widens the gap between social work practitioners and educators and limits clients' access to empirically-supported services. The agency/university collaboration for client outcome assessment as described in this paper capitalizes on the special competencies of agency-based workers and university-based educators. We advocate for integration of the doer and thinker roles within the person of each collaborator. This integrative approach helps agency and university participants respect the diverse and complex issues routinely encountered by social work professionals and maximizes opportunities to combine experiential, theoretical, and empirical learning (Sachdev, 2000).

\section{OUTCOME ASSESSMENT: COLLABORATION OPTIONS}

Agency administrators and university educators may choose from a variety of options as they consider implementing outcome-assessment focused evaluation projects. The collaborators may, for example:

(a) employ a research specialist as an agency staff member to fulfill various program and practice evaluation functions; 
(b) contract with a for-profit research firm to conduct outcome assessment evaluations;

(c) contract with a university program to conduct outcome assessment research; or

(d) collaborate with a university program regarding outcome assessment evaluation and capacity-building.

As the title suggests, this paper addresses the last option, that of agency/university collaboration. In this approach, each collaborator brings special expertise to the enterprise and all may expect to benefit from the interaction. In the agency/university model, collaboration can be defined as: "The process of shared creation, (with) two or more individuals with complementary skills interacting to create a shared understanding where none had previously existed or could have come to on their own" (Schrage, 1995, p. 33). With collaboration, all participants willingly sacrifice some autonomy and fully acknowledge the need for the special expertise of the other party in order to achieve each other's goals. In this instance, the agency develops a new capacity and the university increases its understanding of direct practice while discharging its community service obligation by looking at agencybased practice. In essence, the collaborative process involves a search for meaningful common ground by both the researchers and practitioners (Meyer, 1992).

The agency/university collaboration model draws on concepts of participatory action research. While approaches to participatory research usually engage community persons in the research process, they have not been fully applied in collaborative efforts by educators and practitioners to develop an outcome assessment climate in agencies (Altpeter, Schopler, Galinsky \& Pennell, 1999). Participatory research may serve as a means to bring agency practitioners actively into the evaluation process rather than simply treating them and their organization as a place merely to conduct research, a source of data, or variables to be manipulated (Ansley \& Gaventa, 1997). Herda (1999) identifies three potential benefits of participatory research: new knowledge, mutual education, and solutions for specific problems. "Even more important than new knowledge and solutions are the new understandings that can take place among people working together" (Herda, 1999, p. 6). Only by generating new ways to look at practice and outcome assessment can reframing the thinker and doer dichotomy become possible.

\section{CASE STUDY: ASSESSING A PARENTING PROGRAM'S CLIENT OUTCOMES}

\section{First Phase of Collaboration: Preparing for Outcome Assessment Work}

The director of a large program within a multi-service, sectarian agency initiated the agency/university collaboration to assess the outcomes of a parenting program. The director described the process by which she arrived at the need for evaluation skills as follows:

Three years ago, we obtained a small grant that allowed us to focus on designing services for pregnant women, parenting families, and adolescents at risk of becoming parents. The RFP asked us to specify our objectives and the activities that we felt would meet those objectives. We also had to submit a plan on how we would evaluate the services we were delivering. Since other programs within the agency already had received funding for this type of 
program, we struggled primarily over the activities and objectives and more or less copied the evaluation submitted by the other programs.

We wrote that we would conduct comprehensive intakes, and maintain case records and group service logs (including dates of service, nature of service, and need for additional services); these would be reviewed monthly; case records would document client goals, observations, progress, referrals, and outcomes; there would be weekly individual supervision to review individual's work and processes and we would write quarterly reports to address progress in meeting objectives. As you can see, the questions of who is going to analyze all this and how are we ever really going to look at whether any of this is really effective were not answered.

This broad evaluation statement was sufficient to obtain first-year funding for implementing the parenting program. However, by the second year, the agency experienced increased pressure from the funding source to develop a more specific evaluation plan. Since the agency director had previously hired a social work professor to work with the staff to enhance their group work skills, she consulted with the professor about how the university might help the agency conduct a program evaluation. The professor, in turn, consulted with a colleague to determine whether he would participate in the effort. The two faculty members (one a practice teacher with an interest in research and the other a researcher with an interest in practice), agreed to voluntarily work with the agency to develop methods for assessing the outcomes of parenting programs. At the time, the educators recall thinking that the collaboration was an opportunity to look at social group work with a specific population and learn more about that practice. They were unsure whether the agency would accept the concept that the evaluation might show the program in an unfavorable light, but felt that despite the results, the effort would help both sides learn more about practice and about how to integrate systematic assessment of outcomes into agency practice.

The agency director requested reallocation of some of the grant monies for research expenses. The foundation readily agreed, anticipating that the outcome assessment efforts might provide objective data that could help to publicize and expand the program. This experience helped all parties identify their self- and mutual interests. A contract that served the needs of all constituents was developed. All parties explicated their interests and goals. They discussed what realistically could be achieved and established reasonable timeframes. They also anticipated numerous practical, professional, and ethical challenges associated with the collaborative research endeavor.

\section{Second Phase of Collaboration: Beginning Outcome Assessment Work}

Following agreement concerning the contract, the university faculty, agency director, social work supervisor, and service coordinator responsible for working with the parent client groups met to develop a logic model. The collaborative group first identified the problems the program planned to ameliorate. The collaborators then explored what could be different if the problems were resolved, and, as a part of this solution-focused process, identified the program's proximal goals (i.e., more immediate outcomes that may be indicators of subsequent long- 
term success). For example, in this program, an understanding of what might be expected of children at different ages could help parents set realistic expectations of their child and might lead to a better parent-child relationship in the longterm. Defining the program's intended goals was an important step in helping the agency move toward integrating a research perspective into practice.

As described by the agency director:

After we got the funds, we set up a meeting with the professors, supervisor, the staff member responsible for the program, and myself. What we wanted to do was just look at our objectives. I had a vague recollection of research from when I was in school but was not prepared for being forced to look at what we were trying to accomplish. At first, as a director, I felt defensive. I thought, "What do you mean how do we know it worked? Of course it worked! Let me tell you about Sally!" And on we went with these anecdotal stories. That was how we had always articulated to funding streams how we knew the program was working. We would give an example. We tell them about the history of Sally. Only we didn't have much information about Joe, Rose, and everybody else who was also in the program.

As a collaborative effort, the university collaborators' function was not to define the program for the agency or to document its effectiveness. Rather, it was to help practitioners learn how to conduct the assessment process. The participants collectively discussed the relationships among the interventions, the goals of the program, and the techniques to assess client outcomes, all within the pressures of agency life. The staff worked toward specifying those interventions they would use and how each aspect of the program could be tied to a specific outcome. The specification process often led to reconsideration of the planned interventions or the anticipated goal. For instance, the collaborators quickly realized that the general statement, "Teenage parents would receive mutual aid group work services," was not sufficiently specific. They revised the description to incorporate the planned activities for each parenting group session and how those activities contributed to the overall goals.

After establishing a common understanding of program objectives, the collaborators worked to define desired outcomes and select measures. For psycho-educational components, such as the nutrition/cooking session, the collaborative team developed a knowledge scale that reflected what staff expected clients to know upon completion of the program. Items about client attitudes towards the group experience were also included. Once the goals of increasing parenting skills, empowerment, and social support were identified, standardized measurements were selected for pre- and post-testing. These included the AdultAdolescent Parenting Inventory (Bavoleck, 1984), the Multidimensional Scale of Perceived Social Support (Zimet, Dahlem, Zimet \& Farley, 1988), the Revised UCLA Loneliness Scale (Russell, People \& Catriona, 1980), and the Locus of Control Scale (Pearlin \& Schooler, 1978). During this process, faculty members shared their knowledge of applicable instruments and their expertise in scale development. They helped agency staff to better understand measurement options and select the most appropriate assessment tools. The team also identified demographic information needed to better understand the client population 
and incorporated means to collect the pertinent data. The agency director noted:

Having to articulate all this and giving the workers room to talk about how they felt and what they thought, we looked at the pre-post-test design, at the instrument, itself, and the content areas. We then talked about client reactions. The professors were willing to redesign content and forms. We looked at the funding of the study, the demographic characteristics of the clients, the effectiveness, and future directions. It was very much a process. What we had learned was that you really need to go through this process to bring people on board.

At about this point, the nature of the challenge moved beyond gaining "buy in" to the plan. It now became an issue of how to bring the supervisor and line workers on board. As the agency director noted:

This was a journey in itself, as staff felt this was a lot of testing and struggled, sometimes successfully and sometimes not, to incorporate the testing package into the intake process.

Despite energetic efforts to engage staff in the assessment process, by the end of the first year, only a small sample of pre- and post-test instruments had been collected. The program coordinator - the key direct practitioner-viewed the task as burdensome. Apparently, the collaborators had focused too extensively on developing the evaluation and not enough time was spent addressing the coordinator's concerns. When confronted, the coordinator admitted that she had not used the instrument package because she "did not know enough about them to complete it." Once the coordinator resigned, the director reviewed case records and found a copy of the following note to a client: "Dear Mary, Please come back in so we can administer the post-test that my director wants us to administer." Clearly, there were varying levels of engagement among staff and clients.

By the close of the first year of the agency/university collaboration, the participants were frustrated that more had not been accomplished. However, they had a better understanding of what outcome assessment entails. Unexpectedly, the collaborators found that the most valuable source of information was the face sheet that accompanied all pre- and post-tests. The face sheets captured demographic and service participation data for each client. When aggregated, they yielded a portrait of the client population that was, in some ways, unexpected. The findings resulted in reassessment of program outreach and service delivery strategies, and as the director states, an expansion of the collaboration:

More work needed to be done in looking at ways to measure outcome in our client service delivery model that people can buy into, that staff did not feel is just another burden, and that we could incorporate into our entire program. We went back to the funding source and said we have begun this process and want to continue it. They again gave permission. We were now at a different stage in our collaboration and set up meetings with staff in other parenting programs in the agency. We invited them to join us in the process. Four programs said they wanted to join the effort. At first, some of the directors were 
reluctant. It meant more work for them was how they saw it. So, we engaged in a series of meetings that the faculty collaborators attended. Our approach was broader and different from the way research had been discussed before. For example, one agenda started with "Purpose of the Program for Client, Funder, \& Agency."

We again looked at the pre-post-test design. Through articulating all this, we gave the newer participants room to talk about how they felt and what they thought. It was very much a process. We are so consumed on a day-to-day basis with the work we have to do; it is difficult sometimes to stand back and ask what are we doing and how we can articulate it to others.

\section{Third Phase of Collaboration: Engaging in Outcome Assessment Work}

Through additional collaborative efforts, an expanded program base, and greater personal investment by staff, a general commitment to collect needed assessment required data was enhanced. During this phase, most problems with data collection involved difficulties clients had in their attempts to complete the instruments. Collaborating faculty members encouraged staff members' development and incorporation of an expanded conception of their role-one that included both the provision of service and the evaluation of service outcomes. There were extensive discussions about how assessment activities could enhance their work with clients. Of course, complex issues arose. For example, mandated clients were concerned about what would be done with the data. Children sometimes distracted parents while they completed the instruments. Clients occasionally challenged some questionnaire items as too personal and, after completing the instruments, some also wanted to know what were the right answers.

Collaborators were concerned that the instruments measured clients' knowledge but not necessarily their actions. Many of these issues highlight the practical and ethical complexities of practice research. Clearly, some workers were worried that they would not be able to demonstrate that they were doing a good job. They were reluctant to gather data. Others welcomed the opportunity to broaden their understanding of clients.

In a collaborative effort, it is not the faculty members' direct responsibility to ensure that the staff meet data collection requirements. However, many projects have been jeopardized through inadequate data collection, leading the educators to encourage staff participation. In this case study, faculty members were involved in staff discussions about the process as the project proceeded. Ultimately, design, implementation, and analysis became the shared responsibilities of all participants.

Throughout the second year of the collaboration, several meetings were held to discuss progress. Discussions centered around data collection issues, the relevance and utility of the instruments, translation (i.e., language) problems, and client concerns about their performance on the test. Halfway through the year, preliminary findings were shared with all participants and the possible significance of some of the results was discussed. University collaborators promised to provide the agency with data that could be used in preparing funding requests for the following year's programming. 
These meetings and the educators' willingness to modify instruments as needed developed a climate of collaborative learning, rather than one of judgment. Discussions demonstrated the usefulness of data collection and strengthened commitment to the collaboration. Pre- and post-test data were obtained for many more clients. The funding source expressed an interest in obtaining additional assessment information to help them respond to questions about the effectiveness of the program. The director reported:

\section{One of the reasons for the funding stream being on board was that they also}

had to articulate whether their money was doing any good.

At the close of the second year of collaboration, two of the three programs obtained most of the necessary pre- and post-test data. The worker in the remaining program still had difficulty administering the questionnaires. Findings from the two settings showed statistically significant improvement in the areas of parents' degree of role reversal with their child and excessive use of physical punishment, as measured through the AAPI. The respondents also showed a statistically significant improvement in their locus of control. In the areas of loneliness and perceived social support, improvements did not achieve the intended level of statistical significance. Workers discussed what specific activities might have accounted for the changes in some areas and not in others, thereby, maintaining a connection between findings and practice.

Certain aspects of research frighten many social workers. For example, computerized data analysis often provokes anxiety in even highly seasoned professionals (Epstein, 1987). During the early years of the project, faculty members undertook these tasks. As time passed, however, even these activities became more evenly distributed. Agency staff members, however, were extensively involved in defining the questions that they wanted answered. They were also active during hands-on discussions of the actual tables that reflected the findings. About half-way through the second year, faculty collaborators worked with staff in a quarterly meeting to define what questions they wanted answered at that time. Faculty members helped practitioners understand whether the questions posed could be answered by the data. One educator brought a portable computer, complete with the data set, to the team meeting so that agency staff members could observe how answers to questions could immediately be derived from the data set.

Participants from each program received information about their own as well as all programs, combined. This allowed for discussion about how factors such as community, context, and population may affect the results. Some staff and supervisors expressed an interest in learning how to conduct various analyses and requested copies of the data set so they might practice. In future years, the collaborators hope to help programs develop their own capacity for computerized data analysis.

As the collaborators plan for the next phase of the project, the agency director observed:

Staff are now excited about the work as we enter the third year of the process. The agency is excited about the work. The funders are hoping they can share the findings with other agencies and the findings from the second year are being written up for them. 
Since beginning the collaboration, the agency has become intensively involved in an accreditation review. The outcome assessment process prepared them to articulate their goals and intervention approaches. The agency director indicated that:

The accrediting teams are looking at what kind of tools are in place and how they address your services. They don't want to hear about how Joe is doing! They want to know what makes the difference.

The agency's participation in this collaborative effort served as a visible demonstration of their commitment to quality practice, to sharing their work with the field, and to outcome assessment. The agency's accreditation review contained specific reference to the collaboration as an extremely important and positive activity.

\section{CONSIDERATIONS IN ESTABLISHING A COLLABORATIVE PROJECT TO ASSESS CLIENT OUTCOMES}

In looking at the obstacles to collaboration between practitioners and researchers, Galinsky, Turnbull, Meglin \&Wilner (1993) suggested "a strategy that unifies practitioners and researchers that is relevant to practice has not been identified to date" (p. 440). As this case study indicates, the challenges are formidable. However, the agency/university experience yielded four guidelines for effective collaboration.

\section{Recognition of Institutional Demands}

In times of cutbacks and competition for resources, in particular, social agencies must explain what they are doing and prove the value of their service. However, most social service organizations have not historically evaluated their services on a systematic basis. In the contemporary context, it is in the agencies' self-interest to use research to inform action and enhance decision-making, and to assess outcomes (Patton, 1990). Proposals almost universally require statements of goals or objectives, and many expect a direct link between these goals and a proposed outcome assessment strategy. Federal agencies routinely require a rigorous evaluation component in any request for funds (OAPP, 2001; FIPSE, 2001).

The Council on Social Work Education's Curriculum Policy Statement (COA, 1994) articulates the imperative for social work education programs to be engaged in service to the practice community as follows:

Programs of social work education maintain close, reciprocal, and ongoing relationships with social work practitioners and with groups and organizations that promote, provide, or seek to influence social policies and social work services.

Programs have a variety of choices regarding how to meet this challenge. While CSWE does not mandate specific ways in which to address community needs, they do identify program-initiated collaborative projects and agency consultation by faculty as key areas for consideration. Thus, community service by faculty, while ranking behind publications and teaching in making tenure decisions, is considered a component of responsible social work education (Euster \& Weinbach, 1983). 


\section{Ownership of Collaborative Process}

The first step in the collaboration process is the identification of self- and common interests of the involved parties. When these interests are not clear, the collaboration may dissolve with one party feeling used by another. This is particularly likely when the project is externally funded. Money often raises power and control issues that must be addressed and resolved before collaboration can proceed. In this case, the allocation of funds toward outcome assessment represented a form of direct investment by the agency involved in the collaboration. Although agency compensation to university participants was modest and primarily used for computer processing and duplication costs, it served to strengthen the contractual relationship among collaborators.

Focusing on common goals, rather than on methodological considerations, fosters the initial dialogue among participants (Proctor, 1990). By focusing on research questions and what answers will be sought, practitioners' concerns about the educator/researcher controlling the agenda and the process may be allayed. At the same time, the educator/researcher begins to better understand the frames of reference of agency staff. Understanding is furthered through discussion of resources, always an important part of the initial phase. Such discussions almost always surface concerns that involvement in research activities will divert scarce resources from client services. These concerns require full and open discussion.

Educators and practitioners need a basic understanding of what other collaborators are doing. Expertise does not imply superiority or domination. Rather, in this context, expertise refers to the special knowledge and skill needed to design and implement a relevant, purposeful, ethical, and high-quality evaluation or practice activity. Collaborators must share a common understanding of the assessment and treatment process and recognize the special kinds of expertise that others have that can be used during the enterprise.

One benefit of the collaborative effort is developing an increased comfort with social work intervention as a shared enterprise. Outcome assessment often leads to a reconceptualization of service to clients as the work of the agency, rather than the work of individual professionals. The process enlarges the perspective, often bringing agency administration and staff into a collective activity and ownership. Sometimes, researchers delude themselves by thinking that the commitment of the agency director represents the commitment of the staff as well. Direct service workers tend to be committed to service. They may see research activities as detracting from their primary mission. Collaborators build staff commitment by opening the research process to them and by addressing the questions for which they need answers.

From the onset of the collaboration, all members were asked to listen carefully to one another, adopt a non-judgmental attitude, interact respectfully, and share power in the best interest of the clients (Solomon \& Mellor, 1992). In an effort to encourage a genuine collaboration, the educators resisted temptations to assume control of the agenda. Collaboration is a process through which all participants may benefit. Indeed, through the collaborative activities, faculty learned a great deal about the day-to-day realities of practice and, as a result, enabled them to 
bring the changing and challenging nature of contemporary social work back to their students in the classroom.

\section{Realistic Appraisal of Risks}

Any project such as this involves very real risks for each participant and for the organizations involved. Unless these risks are openly explored, genuine collaboration is unlikely. Reluctance to participate fully is commonly associated with risks the project places on participants. Agencies risk learning that some or all of their services are ineffective or even harmful. Access to such knowledge would highlight a need for change and challenge the status quo of agency life (Hanson, 1998).

Social workers are also at risk. As the service providers, the nature and impact of their work becomes essentially public through outcome assessment activities. In most settings, they will be blamed for program failures.

Even with the approval of human subjects' review panels, clients may also be at some risk. Most of the time, of course, clients benefit from increased supervision and assessment; occasionally, this may lead to unwanted or unexpected consequences. These may be dramatic, such as in child welfare settings where documentary evidence of client progress gained through outcome assessment efforts affects decisions about family reunification. Unintended effects may also be less dramatic, although no less meaningful. For instance, clients may become embarrassed or self-conscious when due to certain questionnaire items, they reveal more intimate or personal information than they would actually prefer.

Although it might appear that the faculty members would be exposed to relatively few risks, there may be some. Studies that do not meet the gold standard of randomized controlled trial research may deplete time and energy that could otherwise be invested in other scholarly pursuits. Some argue that collaborative processes result in lower quality research, and may contribute to unfavorable decisions about tenure or promotion. For most faculty members, however, the potential gains far outweigh the risks. The focus of the collaborative outcome assessment approach is on developing a commitment to practice assessment in a climate of inquiry and capacity building. Such collaborative enterprises serve to build and advance the profession by encouraging outcome assessment as an ongoing part of agency practice and classroom learning.

\section{Pacing of Work}

Collaborative endeavors are rarely smooth processes. Regardless of the strength of an agency administrator's commitment to the assessment of program outcomes, there are palpable concerns for survival in the new accountability context. Administrators tend to be defensive when their traditional patterns of service delivery are challenged and the effectiveness of all forms of practice is open to question. University collaborators need to explore whether agency professionals genuinely endorse outcome assessment initiatives. They must anticipate the possibility that the findings may show the program to be ineffective. Similarly, agency administrators need to openly discuss the depth of their commitment to the agency with faculty collaborators. As shown in this case study, the process of helping the agency develop a climate supportive of outcome assessment tends to take a considerable amount of time and a great deal of patience. 
In such collaborations, the pace of change and implementation should be established by the group as a whole. Early meetings need to be devoted to deciding what the parties can feasibly do together. As the participants work out the details of a shared program or activity, they become familiar with each other's special language and establish shared goals and objectives. The collaborative relationship is characterized by mutuality and reciprocity-a balance of giving and receiving (Skaff, 1988). Trust and commitment must be present in the relationship, informing a process in which participants expand their capacities as they gain new expertise from the interaction.

The process is hardly tension-free. The progress may be slow and the results modest. The nature and amount of data generated may not appear worth the investment. Clearly, the academic researchers could intercede to make things right, but that would defeat the very essence of the effort as a collaboration. A preemptive intervention would definitively set the educator apart from the agency participants, especially the direct service workers. As Cheetham (1992) points out, educators and practitioners must acknowledge that effectiveness research is a "long journey," one which involves "a treaty neither to be too greedy of research endeavors nor evasive about what has and has not been achieved" (p. 279). If the educator can accept the agency's pace of change, much can be gained. Together, the educator and the clinician can share different perspectives about the intervention process. A genuine climate of inquiry can emerge in which university collaborators may learn about the struggles of agency practice and participate in the development and validation of new approaches to service.

\section{SUMMARY}

The agency/university outcomes assessment collaboration model described in this article was drawn from many sources. It is, however, primarily a social work approach, bringing client, agency, and educational systems together. In practice, it must be ethically sound and implemented in a manner that enhances opportunities for participant empowerment. When successful, the agency/university collaboration model is "critical, integral, personal, and responsible" (Cohen, 1995). The collaboration becomes critical as agency personnel recognize that outcome assessment is tied to its survival. The educators' acceptance of the collaboration meets their need to stay abreast of the realities of current practice. The collaboration is integral to the agency to the extent that staff accept their participation in outcome assessment as central to the delivery of quality service to clients, rather than an extra bit of busywork. Similarly, educators' need to be in touch with new developments in the field by maintaining close ties to day-to-day practice and the university's goal to advance practice in the field and make the work integral to the university's mission.

Practitioners and educators also make a personal connection to the collaboration. Without an internalized belief that assessment is important to improving services and refining practice skills, practitioners and educators will not invest the energy needed for success. As noted earlier, when such ownership is not present, implementation is spotty, and possibly detrimental to clients. Finally, the collaboration model is responsible, in that mutual respect and openness to new opportunities for learning characterize the work. 
The model represents a process through which social work faculty members can collaborate with agency staff to develop and implement a project of benefit to all constituents. The impact of collaboration multiplies geometrically as practitioners become more aware of their own practice and share experiences with others, as administrators better articulate their services to boards and external funders, and as faculty return to the social work classroom with reality-tested experience. This approach has the potential to increase the empirical base of social work practice by helping practitioners systematically generate useful data concerning the effects of their service activities. By working together throughout the entire process of formulating questions, identifying clear objectives, selecting or creating meaningful measurement tools, and performing evaluation research that validly captures the effects of service interventions, collaborative endeavors may help unite practitioners and educators in their common professional enterprise.

\section{References}

Altpeter, M., Schopler, J.H., Galinsky, M.J., \& Pennell, J. (1999). Participatory research as social work practice: When is it viable? Journal of Progressive Human Services, 10(2), 31-53.

Ansley, F. \& Gaventa, J. (1997). Researching for democracy and democratizing research. Change, 29(1), 4653.

Austin, D.M. (1999). A report on progress in the development of research resources in social work. Research on Social Work Practice, 9(6), 673-707.

Austin, D.M. (1992). Findings of the NIMH task force on social work research. Research on Social Work Practice, 2(3), 311-322.

Bavolek, S.J. (1984). Handbook for the adult-adolescent parenting inventory. Eau Claire, WI: Family Development Associates, Inc.

Blythe, B.Y. (1992). Evolution and future development of clinical research utilization in agency settings. In A. J. Grasso \& I. Epstein (Eds.), Research utilization in the social services: Innovations for practice and administration (pp. 251-299). NY: Haworth.

Cheetham, J. (1992). Evaluating social work effectiveness. Research in Social Work Practice, 2(3), 265-287.

Chernesky, R.H. (1997). Funding substance abuse prevention programs for youth. In E. Norman (Ed.), Drug-free youth: A compendium for prevention specialists (pp. 131-156). NY: Garland.

Christ, G., Siegel, K., \&Weinstein, L. (1995). Developing a social work research unit within a hospital social work department. Health and Social Work, 20(1), 60-68.

Cohen, C.S. (1995). Making it happen: From great idea to successful support group program. Social Work with Groups, 18(1), 67-80.

Commission on Accreditation. (1994). Handbook of accreditation standards and procedures. Alexandria, VA: Council on Social Work Education.

Epstein, I. (1987). Pedagogy of the perturbed: Teaching research to the reluctants. Journal of Teaching in Social Work, 1(1), 71-89.

Euster, G.L., \& Weinbach, R.W. (1983). University rewards for faculty community service. Journal of Education for Social Work, 19(1), 108-114.

Fund for the Improvement of Post Secondary Education. (2001). Competition guidelines and application materials. [On-line] [Available]: http://www.ed.gov/offices/OPE/FIPSE/compete.html.

Fraser, M.W., Jenson, J.M., \& Lewis, R.E. (1993). Research training in social work: The continuum is not a continuum. Journal of Social Work Education, 29(1), 46-62.

Galinsky, M.J., Turnbull, J.E., Meglin, D.E., \& Wilner, M.E. (1993). Confronting the reality of collaborative practice research: Issues of practice, design, measurement, and team development. Social Work, 38(4), 440-449. 
Hanson, M. (1998). Practice in organizations. In M.A. Mattaini, C.T. Lowery \& C.H. Meyer, (Eds). The foundations of social work practice: A graduate text (2ND ed., pp. 240-264). Washington, D.C: NASW.

Herda, E. A. (1999). Research conversations and narrative: A critical hermeneutic orientation in participatory inquiry. Westport, CT: Praeger.

Lindsey, D., \& Kirk, S.A. (1992). The continuing crisis in social work research: Conundrum or solvable problem? An essay review. Journal of Social Work Education, 28(3), 370-382.

Meyer, C. (1992). Social work assessment: Is there an empirical base? Research on Social Work Practice, 2(3), 297-305.

NASW. (1996, 1998). Code of Ethics. Washington, D.C.: NASW.

Office of Adolescent Parenting and Pregnancy. (2001). Guidelines for adolescent family life programs. [Online] [Available]: http://www.hhs.gov/opa/titlexx/oapp.html.

Patton, M.Q. (1990). Qualitative evaluation methods. Newbury Park, CA: Sage.

Pearlin, L.I., \& Schooler, C. (1978). The structure of coping. Journal of Health and Social Behavior, 19(1), 221.

Proctor, E. (1990). Evaluating clinical practice: Issues of purpose and design. Social Work Research and Abstracts, 26(1), 32-40.

Russell, D., People, L.A., \& Catriona, C.E. (1980). The revised UCLA Loneliness Scale: Concurrent and discriminate validity evidence. Journal of Personality and Social Psychology, 39, 472-480.

Sachdev, P. (2000). From the editor. Advances in Social Work, 9(1), i-vi.

Schrage, M. (1995). No more teams: Mastering the dynamics of creative collaboration. NY: Doubleday.

Skaff, L.F (1988). Child maltreatment coordinating committees for effective service delivery. Child Welfare, $67(3), 217-230$.

Solomon, R., \& Mellor, M.J. (1992). Interdisciplinary geriatric education: The new kid on the block. Journal of Gerontological Social Work, 19(3/4),175-186.

Witkin, S.L. (1995). Wither social work research? An essay review. Social Work, 40(3), 424-428.

Zimet, G.D., Dahlem, N.W., Zimet, S.G., \& Farley, G.K. (1988). The multidimensional scale of perceived social support. Journal of Personality Assessment, 52, 30-41.

\section{Author's Note:}

Address correspondence to: Carol S. Cohen, D.S.W., C.S.W., Assistant Professor and Program Director, B.A. Program in Social Work, Fordham University Graduate School of Social Service, 113 West 60th Street, New York, New York 10023 USA, ccohen@fordham.edu. 